\title{
Zoledronic acid impairs myeloid differentiation to tumour-associated macrophages in mesothelioma
}

\author{
JD Veltman', MEH Lambers', M van Nimwegen', RW Hendriks', HC Hoogsteden', JPJJ Hegmans' \\ and JGJV Aerts*,1,2
}

'Department of Pulmonary Medicine, Erasmus Medical Centre Rotterdam, PO Box 2040, Rotterdam 3000 CA, The Netherlands; ${ }^{2}$ Departement of Pulmonary Diseases, Amphia Hospital, molengracht 21, Breda 4818CK, The Netherlands

BACKGROUND: Suppressive immune cells present in tumour microenvironments are known to augment tumour growth and hamper efficacy of antitumour therapies. The amino-bisphosphonate Zoledronic acid (ZA) is considered as an antitumour agent, as recent studies showed that ZA prolongs disease-free survival in cancer patients. The exact mechanism is a topic of debate; it has been suggested that ZA targets tumour-associated macrophages (TAMs).

METHODS: We investigate the role of ZA on the myeloid differentiation to TAMs in murine mesothelioma in vivo and in vitro. Mice were intraperitoneally inoculated with a lethal dose of mesothelioma tumour cells and treated with ZA to determine the effects on myeloid differentiation and survival.

RESULTS: We show that ZA impaired myeloid differentiation. Inhibition of myeloid differentiation led to a reduction in TAMs, but the number of immature myeloid cells with myeloid-derived suppressor cell (MDSC) characteristics was increased. In addition, ZA affects the phenotype of macrophages leading to reduced level of TAM-associated cytokines in the tumour microenvironment. No improvement of survival was observed.

CONCLUSION: We conclude that ZA leads to a reduction in macrophages and impairs polarisation towards an M2 phenotype, but this was associated with an increase in the number of immature myeloid cells, which might diminish the effects of ZA on survival. British Journal of Cancer (2010) 103, 629-64I. doi:10.1038/sj.bjc.66058I4 www.bjcancer.com

Published online 27 July 2010

(c) 2010 Cancer Research UK

Keywords: Zoledronic acid; myeloid differentiation; macrophages; myeloid-derived suppressor cells; malignant mesothelioma

Recently, cancer-related inflammation was recognised as the seventh hallmark of cancer (Colotta et al, 2009). Infiltration of inflammatory cells into tumour tissues can be detected in many cancers. These infiltrating immune cells can possess immune stimulatory (antitumour activity) or immune suppressive capacity and thus promote tumour progression. In the tumour microenvironment of a progressing tumour, regulatory $\mathrm{T}$ cells, myeloid-derived suppressor cells (MDSCs) and tumour-associated macrophages (TAMs) have an important role in facilitating tumour growth and immune escape by suppressing antitumour effector cells (Bronte et al, 2001; Hegmans et al, 2006; Sakaguchi et al, 2008; Sica et al, 2008; Allavena et al, 2008b; Gabrilovich and Nagaraj, 2009).

Regulatory $\mathrm{T}$ cells and MDSCs are regarded as immune suppressive, as they are capable of inducing T-cell apoptosis and T-cell tolerance (Nagaraj and Gabrilovich, 2007; Sakaguchi et al, 2009), whereas TAMs are involved in a variety of processes, including angiogenesis, tumour invasion and tumour metastasis (Pollard, 2004; Condeelis and Pollard, 2006). Tumour-associated macrophages are derived from circulating monocytic precursors. Recently, it has been shown that this group of immature myeloid cells can be derived in three different populations, carrying MDSC characteristics, and can also function as a pool of precursor

*Correspondence: Dr JGJV Aerts; E-mail: JAerts@amphia.nl Revised 28 June 2010; accepted 29 June 20I0; published online 27 July 2010 cells for macrophages and endothelial cells. Mononuclear-MDSC (MO-MDSC) harbours immune suppressive capacities, but additionally function as TAM precursors, in contrast to polymorph nuclear-MDSC (PMN-MDSC) and CD $11 b^{\text {high }}$ Gr- $1^{\text {low }}$-MDSC (Bronte and Zanovello, 2005; Nagaraj and Gabrilovich, 2007; Gabrilovich and Nagaraj, 2009; Greifenberg et al, 2009).

Tumour-associated macrophages acquire a polarised phenotype of alternatively activated macrophages (M2), whereas classically activated macrophages (M1) are more associated with inflammation. These two types of macrophages differ in receptor expression, effector function, and cytokine and chemokine productions (Mantovani et al, 2002). By producing pro-angiogenic enzymes, like matrix metalloproteinase 9 (MMP-9), TAMs are able to breakdown the extracellular matrix, leading to the release of pro-angiogenic proteins and growth factors. In addition, TAMs produce vascular endothelial growth factor (VEGF), promoting angiogenesis and recruitment of cells derived from the myeloid lineage (Kusmartsev and Gabrilovich, 2002; Siveen and Kuttan, 2009).

The recruitment of immature myeloid cells is enhanced by the production of chemokine ( $\mathrm{C}-\mathrm{C}$ motif) ligand-2/monocyte-chemotactic protein-1 (CCL-2/MCP-1), which is produced and expressed by TAMs and tumour cells. Within the heterogeneous group of immature myeloid cells, subpopulations are defined, which can further differentiate into mature macrophages, and hence TAMs provide their own precursor cells, which enhances tumour progression (Rossner et al, 2005; Umemura et al, 2008; Greifenberg et al, 2009; Dolcetti et al, 2010). 
Targeting TAMs seems a promising tool to prevent tumour progression, thereby enhancing antitumour therapies. Bisphosphonates have been reported to target macrophages. They were initially prescribed to improve bone density; however, in metastasing cancers, a possible role in prevention of metastasis and prolongation of disease-free survival has been described (Diel et al, 2000, 2008; Gnant et al, 2009). The exact mechanisms by which bisphosphonates prevent disease progression are still a topic of extensive investigations. It has been proposed that bisphosphonates have a direct apoptotic effect on tumour cells (Yoneda et al, 2000; Mundy, 2001, 2002; Fromigue et al, 2003). In addition, indirect effects of bisphosphonates have been reported. It has been suggested that bisphosphonates modulate the immune response and may influence macrophage phenotype (Wolf et al, 2006; Tsagozis et al, 2008; Coscia et al, 2009).

Currently, we are investigating novel therapeutic strategies in mesothelioma, like dendritic cell-based immunotherapy. Mesothelioma is a cancer with dismal prognosis deriving from the layers of the pleural cavity or the peritoneal cavity. As high numbers of TAMs are found in pleural effusions and tumour biopsies in human mesothelioma, we determined the efficacy of a bisphosphonate, Zolendric acid (ZA) (Zometa; Novartis Pharma BV, Arnhem, The Netherlands), on TAM formation and tumour progression in a murine mesothelioma model.

In this study, we analysed the effect of ZA on myeloid differentiation both in vitro and in vivo. In addition, we determined whether ZA changed the phenotype of macrophages. Animal studies were performed to investigate the effect of ZA on survival.

\section{METHODS}

\section{Animals and cell lines}

CBA-j mice (specific pathogen free, female, 6-8 weeks old) were purchased from Harlan (Huntington, UK) and were housed under pathogen-free conditions at the Erasmus MC animal facility. All experiments were approved by the local ethical committee for animal welfare (Erasmus University Committee of Animal Experts, Rotterdam, the Netherlands) and complied with the guidelines for the welfare of animals in experimental neoplasia by the United Kingdom Coordinating Committee on Cancer Research (UKCCCR) and by the Code of Practice of the Dutch Veterinarian Inspection. The AC29 cell line is kindly provided by Professor BWS Robinson (School of Medicine and Pharmacology, Sir Charles Gairdner Hospital Unit, The University of Western Australia, Perth, Australia).

\section{Depletion of macrophages in vivo}

Macrophages were depleted by intraperitoneal (i.p.) injection of liposome-encapsulated clodronate (Dr Nico Van Rooijen, VUmc, FdG, Amsterdams, The Netherlands) (Claassen, 1992; Van Rooijen and Sanders, 1994).

CBA-j mice were i.p. inoculated with a lethal dose of $20 \times 10^{6}$ AC29 tumour cells on day 0. Mice were i.p. injected with $200 \mu \mathrm{l}$ liposome-encapsulated clodronate or liposome-encapsulated PBS at days 5 and 10 after tumour injection. At day 12 mice were killed using $\mathrm{CO}_{2}$. The peritoneal cavity of tumour-bearing mice was washed with $1 \mathrm{ml}$ PBS to obtain peritoneal cells for FACS analysis. All visible tumour material was excised from each mouse and data are expressed as wet weight (accuracy of $0.001 \mathrm{~g}$ ).

Tumour-associated macrophages were defined by the expression of F4/80, MHCII and CD206 (marker for M2 macrophage phenotype).

\section{Immunohistochemistry on tumour biopsies}

Tumour material was obtained 25 days after tumour injection from the peritoneal cavity of tumour-bearing mice. Tumour biopsies were embedded in Tissue-Tek II optimum cutting temperature medium (Miles, Naperville, IL, USA), snap frozen in liquid nitrogen and stored at $-80^{\circ} \mathrm{C}$. Tissue sections $(6 \mu \mathrm{m})$ were cut in an HM-560 cryostat (Microm, Heidelberg, Germany). F4/80 (Dr L Boon, Bioceros, Utrecht, The Netherlands) and CD206 (Serotec, Oxford, UK) primary antibodies were incubated for $1 \mathrm{~h}$ at room temperature. Binding of antibodies was detected using the immunoalkaline phosphatase antialkaline phosphatase method (DAKO, Glostrup, Denmark). Naphthol-AS-MX-phosphate $\left(0.30 \mathrm{mg} \mathrm{ml}^{-1}\right.$; Sigma-Aldrich Chemie BV, Zwijndrecht, The Netherlands) and new fuchsine $\left(160 \mathrm{mg} \mathrm{ml}^{-1}\right.$ in $2 \mathrm{M} \mathrm{HCl}$; Chroma-Gesellschaft, Köngen, Germany) were used as substrate. The specificity of the antibodies was checked using a protein concentration-matched non-relevant monoclonal antibody and PBS.

\section{Flow cytometry}

Spleens were aseptically removed and mechanically dispersed in cold PBS. Cell suspensions were filtered through a $100-\mu \mathrm{m}$ nylon cell strainer (BD Biosciences, Bedford, MA, USA), depleted of erythrocytes by osmotic shock, washed twice in RPMI and adjusted to a concentration of $1 \times 10^{6}$ cells ml $^{-1}$ in FACS buffer.

Splenocytes were stained with the following monoclonal antibodies: Ly6C (FITC), F4/80 (FITC), MHCII (PE), CD11c (PE-Texas red), CD11b (PerCP-Cy5.5), CD31 (PE-Cy7), CD206 (Alexa 647), Ly6G (Alexa Fluor 700), Gr-1 (APC-Cy7) and a fixable live/dead marker in DAPI (Invitrogen, Breda, The Netherlands). The final analysis and graphical output were performed using FlowJo software (Tree Star Inc., Costa Mesa, CA, USA).

\section{Macrophage culture}

Single-cell suspensions of bone marrow, isolated from femurs and tibias of naïve mice, were cultured in RPMI supplemented with $10 \%$ foetal calf serum, $2.5 \mathrm{ml}$ gentamicin $\left(10 \mathrm{mg} \mathrm{m}^{-1}\right)$ (Gibco, Breda, the Netherlands) and $\beta$-mercaptoethanol (Sigma-Alderich) (further referred to as culture medium).

Bone marrow cells were isolated from the femurs and tibias of naïve mice under sterile conditions (Inaba et al, 1992). In short, all muscle tissues are removed with gauze from the bones and placed in a $60-\mathrm{mm}$ dish with $70 \%$ alcohol for $1 \mathrm{~min}$, washed twice with PBS and transferred into a fresh dish with RPMI 1640. Both ends of the bones were cut with scissors in the dish, and then the marrow was flushed out using $2 \mathrm{ml}$ of RPMI 1640 with a syringe and 25 -gauge needle. The tissue was suspended, passed through nylon mesh to remove small pieces of bone and debris, and red cells were lysed with ammonium chloride. A concentration of $10 \mathrm{ng} \mathrm{m}^{-1}$ M-CSF (R\&D systems, Oxon, UK) was used in our bone marrow cultures according to the protocol of Wan et al $(2007,2009)$ ) or $30 \%$ tumour supernatant from AC29 cell culture (at $80 \%$ confluency) was added on day 0 to a culture of $2 \times 10^{6}$ bone marrow-derived cells. AC29 was cultured in RPMI-1640 (Gibco, Paisley, UK) supplemented with GlutaMax, $10 \mathrm{~mm}$ HEPES and 5\% heat-inactivated foetal bovine serum. When confluency reached $80 \%$ (typically 3-4 days), supernatant was collected, centrifuged for $10 \mathrm{~min}$ at $1000 \mathrm{~g}$ to remove cells/cell debris. Supernatant is added to the bone marrow culture at a concentration of $30 \%$. This concentration was selected based on findings by Tsagozis et al (2008), who described that $30 \%$ tumour supernatant generated macrophages with a characteristic TAM phenotype. Zoledronic acid (ZA) (Zometa, Novartis Pharma BV) was added on day 0 to the culture conditions in different concentrations: $0.03,0.15$ or $0.3 \mu \mathrm{M}$. All culture experiments have been repeated five times under comparable conditions.

Mononuclear-MDSCs were isolated from the spleen of tumourbearing mice. Four to six colour samples were sorted using a FACSAria equipped with FACSDIVA software (BD Biosciences). 
After sorting, cells were cultured with M-CSF for 6 days. This experiment has been repeated twice under comparable conditions.

\section{Zoledronic acid treatment protocol}

CBA-j mice were divided into two groups: each group consisting of 10 mice. On day 0 , all mice were i.p. injected with a lethal dose of $20 \times 10^{6}$ AC29 tumour cells. One group was treated daily with subcutaneous (s.c.) ZA injections $\left(100 \mu \mathrm{g} \mathrm{kg}^{-1}, \sim 2.5 \mu \mathrm{g}\right.$ per mice) in $100 \mu \mathrm{l}$ PBS and the other group was treated with $100 \mu \mathrm{l}$ PBS as a control starting at day 5 . This dosage was proven effective and non-toxic in mice (Stathopoulos et al, 2008).

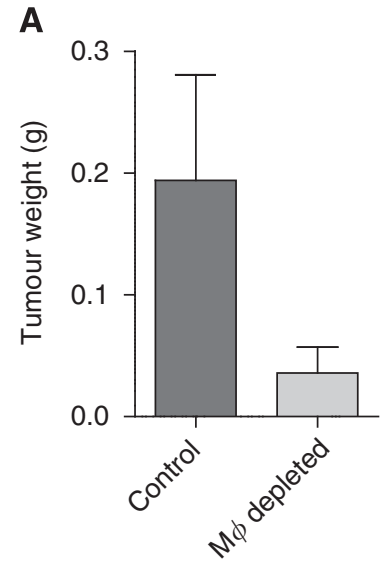

\section{B}
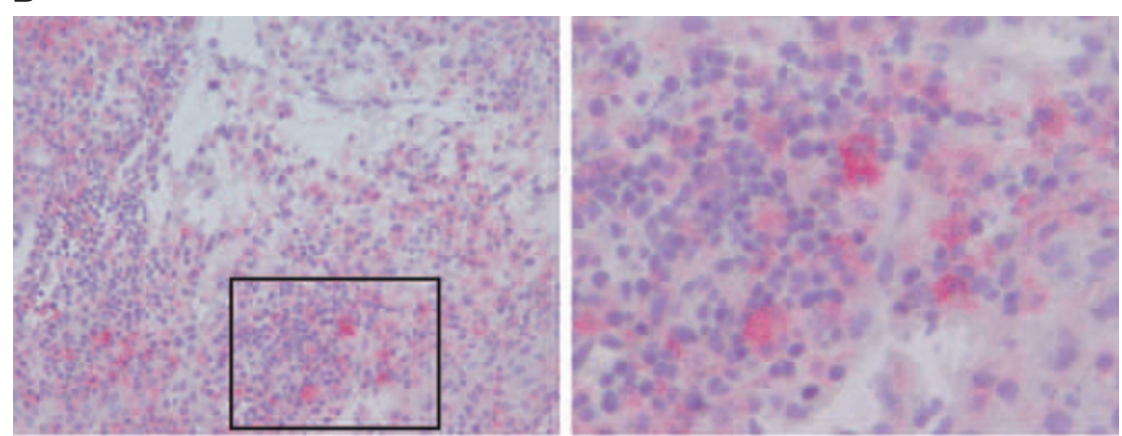

$\mathrm{F} 4 / 80^{+}$
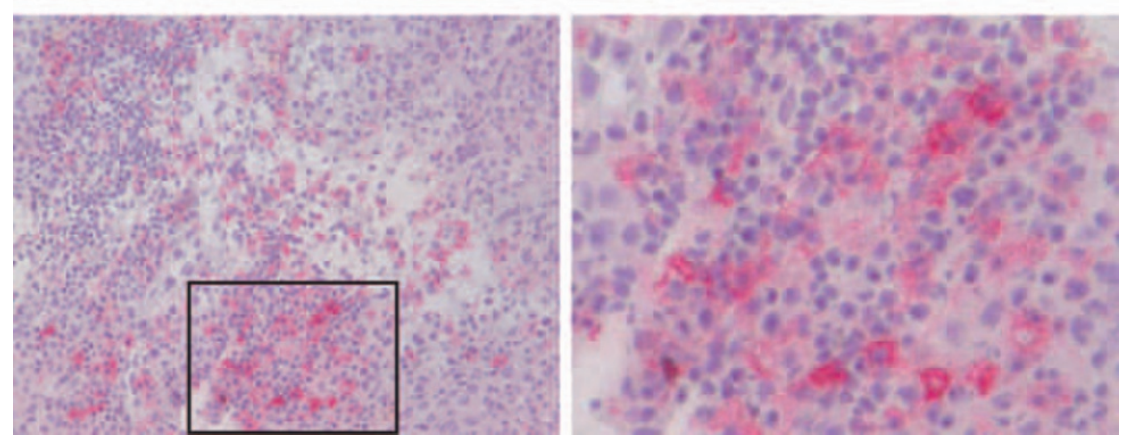
comparable conditions.

\section{Enzyme-linked immunosorbent assay}

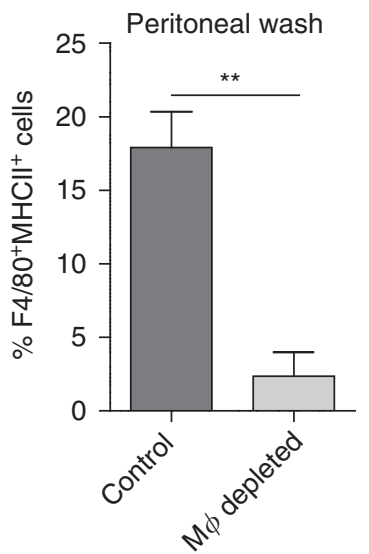

Of both groups, five mice were killed at day 25 . The others were killed when found profoundly ill. The occurrence of tumour growth, body weight, physical well-being and survival were measured for 2 months as described previously (Hegmans et al, 2005). Survival experiments were repeated three times under

To measure cytokine levels, effusion fluid from the peritoneal cavity of tumour-bearing mice was obtained at day 25 after tumour injection. IL-10, IL-12, TNF $\alpha$, IL-6, IL-1 $\beta$, CCL-2 (MCP-1) and

CD206

Figure I Depletion of macrophages inhibits tumour development. On day I, mice were i.p. injected with a lethal dose of AC29 mesothelioma tumour cells and were treated twice with liposome-encapsulated clodronate (macrophage depletion) or liposome-encapsulated PBS (control) on days 5 and 10 after tumour injection $(n=10)$. Twelve days after tumour injection, mice were killed and tumour weight was measured. All visible tumour material was excised from each mouse and data are expressed as wet weight (accuracy of $0.00 \mathrm{I}$ ). FACS analysis was performed to verify the effectiveness of macrophage depletion using liposome-encapsulated clodronate. Tumour biopsies were embedded in Tissue-Tek II and snap frozen in liquid nitrogen. Tissue sections $(6 \mu \mathrm{m})$ were analysed for the presence of macrophages. (A) Effect of macrophage depletion on tumour growth. Tumour growth was observed in all five mice treated with control liposomes; in contrast, only two out of five mice treated with macrophage-depleting liposomes developed visible tumour growth on day 12. Significant reduction in the percentage of $\mathrm{F} 4 / 80^{+} \mathrm{MHCll}^{+}$cells was found in the peritoneal cavity of macrophage-depleted mice $(P=0.0015)$. Tumour weight was found to be lower in macrophage-depleted animals $(P=0.077)$. (B) TAMs in murine mesothelioma. Tumour biopsies of control-treated mice showed infiltration of $\mathrm{F} / 80^{+}$and $\mathrm{CD} 206^{+}$cells (magnification: upper, $\times 200$; lower, $\times 400$ ). $* * *<0.001$. 
VEGF levels in the effusion fluid were determined using a specific ELISA assay (IL-10, IL-12 and TNF $\alpha$ : R\&D systems, Abingdon, UK; IL-6, IL-1 $\beta$ and CCL-2 (MCP-1): BD Biosciences; VEGF: Calbiochem, Darmstadt, Germany). Protocols were followed as per the manufacturer's instructions. Samples were diluted appropriately to ensure that readings were within the limits of accurate detection. Results are expressed as $\mathrm{pg} \mathrm{ml}^{-1}$ of effusion fluid.

\section{Statistical analysis}

Data are expressed as mean \pm s.d. Comparisons between groups were made using $t$-tests. A two-tailed $P$-value $<0.05$ was considered significant. Data presented as a percentage of tumour-free animals were analysed with Kaplan-Meier survival curves, using the log-rank test to determine significance.

\section{RESULTS}

\section{Macrophages are essential in the onset and tumour development}

We investigated the effect of the depletion of macrophages on tumour progression in a murine model for mesothelioma by treating mice with liposome-encapsulated clodronate. These liposomes are readily taken up by phagocytic cells, including macrophages, and induce cell-specific apoptosis after clodronate is set free into the cytoplasm of cells (Claassen, 1992; Van Rooijen and Sanders, 1994).
Mice were i.p. inoculated with a lethal dose of AC29 tumour cells and mice were treated with liposome-encapsulated clodronate or liposome-encapsulated PBS on days 5 and 10 after tumour injection. Mice were killed 12 days after tumour injection. All visible tumour material was excised from each mouse and wet weight was measured (accuracy of $0.001 \mathrm{~g}$. FACS analysis was performed to verify the effectiveness of macrophage depletion (Mantovani et al, 2002; Sica et al, 2006).

Treatment with liposome-encapsulated clodronate significantly reduced the number of macrophages in the peritoneal cavity of tumour inoculated mice $(P=0.0015)$. All mice $(n=5)$ treated with liposome-encapsulated PBS showed profound tumour growth at day 12. Three of the five mice treated with liposome-encapsulated clodronate had no visible tumour. In the case of mice that did develop tumour, tumour growth was less profound (Figure 1A). Macrophages (M1/M2) were found scattered throughout the tumour of a control mice (Figure 1B).

These data show that macrophages have a significant role in the onset and progression of tumour in our murine mesothelioma model.

\section{Zoledonic acid inhibits myeloid differentiation in vitro}

To investigate the effect of ZA on myeloid differentiation in vitro, total bone marrow cells were cultured with M-CSF or 30\% tumour supernatant in the presence or absence of ZA for 6 days using similar culture conditions as described by others (Wan et al, 2007, 2009; Tsagozis et al, 2008). FACS analysis was performed daily. ZA was added in different concentrations: $0.03,0.15$ or $0.30 \mu \mathrm{M}$.
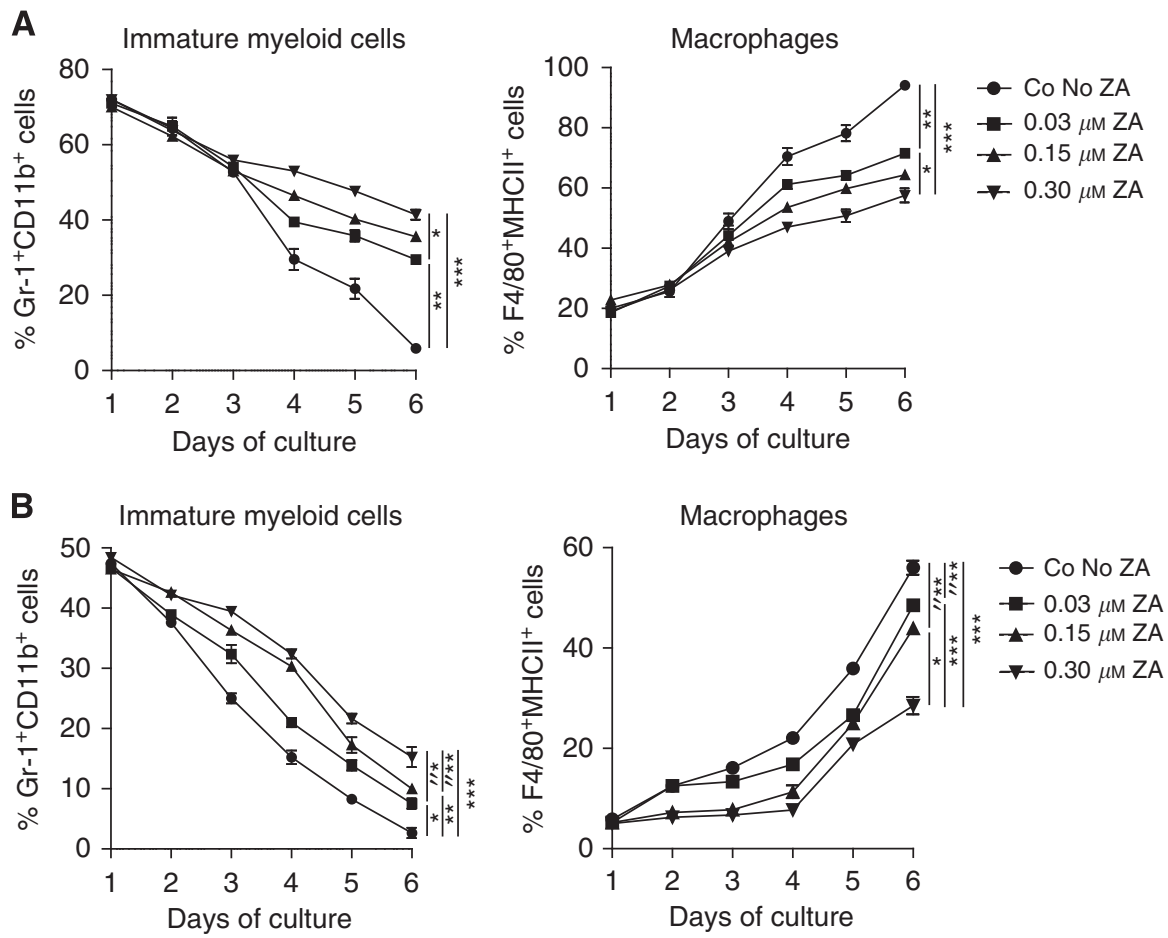

Figure 2 ZA inhibits differentiation of myeloid cells in vitro. The effect of ZA on myeloid differentiation was determined by cultured bone marrow-derived cells with $0.5 \mu \mathrm{g} \mathrm{ml}^{-1} \mathrm{M}$-CSF or RPMI containing 30\% tumour supernatant. Cells were cultured for 6 days. ZA was added to the cultures on day 0 in different concentrations $(0.03,0.15$ or $0.30 \mu \mathrm{M})$. FACS analysis was performed daily. ZA inhibits the downregulation of Gr- ${ }^{+}$cells and the upregulation of F4/80 ${ }^{+}$ and $\mathrm{MHCll}^{+}$cells in a dose-dependent manner. Experiments were repeated and data of five individual experiments were then combined. No significant differences were observed in the number of cells between the different culture conditions. A significant difference was found in the percentage of immature myeloid cells and the percentage of macrophages after 6 days of culture in both, resulting in a higher number of immature cells and a lower number of macrophages in ZA culture conditions. (A) Bone marrow culture with M-CSF: immature myeloid cells, * $P=0.004$; ** $P=0.0001$; $* * * * P<0.000$; macrophages, $* P=0.0003$; $* *<0.0001 ; * * * P=0.005$. (B) Bone marrow culture with $30 \%$ tumour supernatant: immature myeloid cells, $* P=0.016$

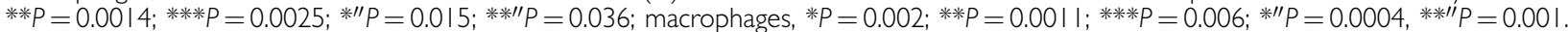


A
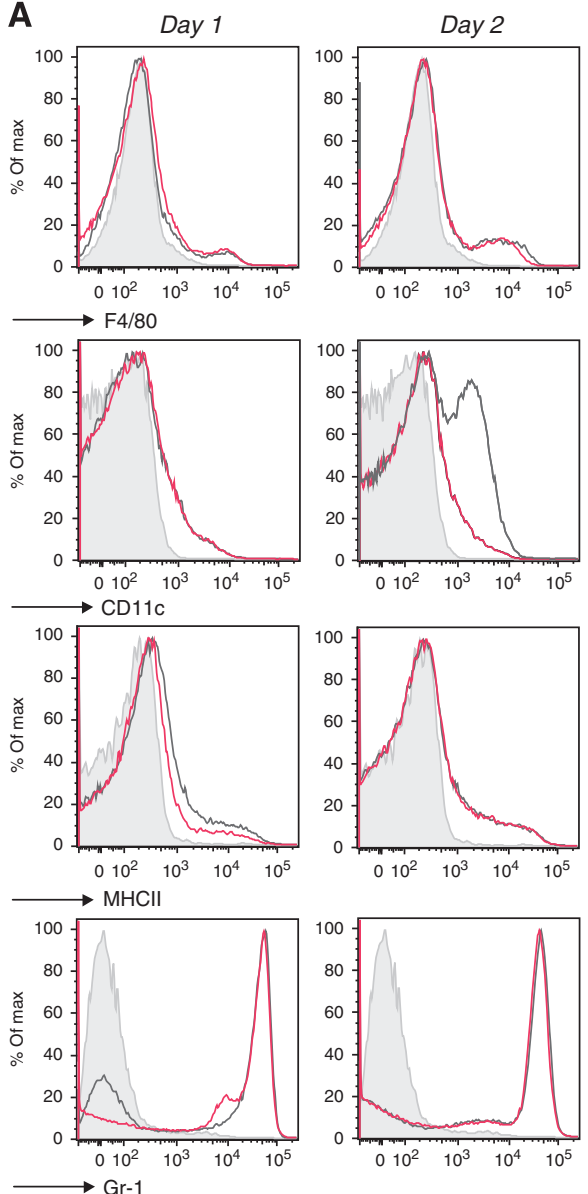

Day 3
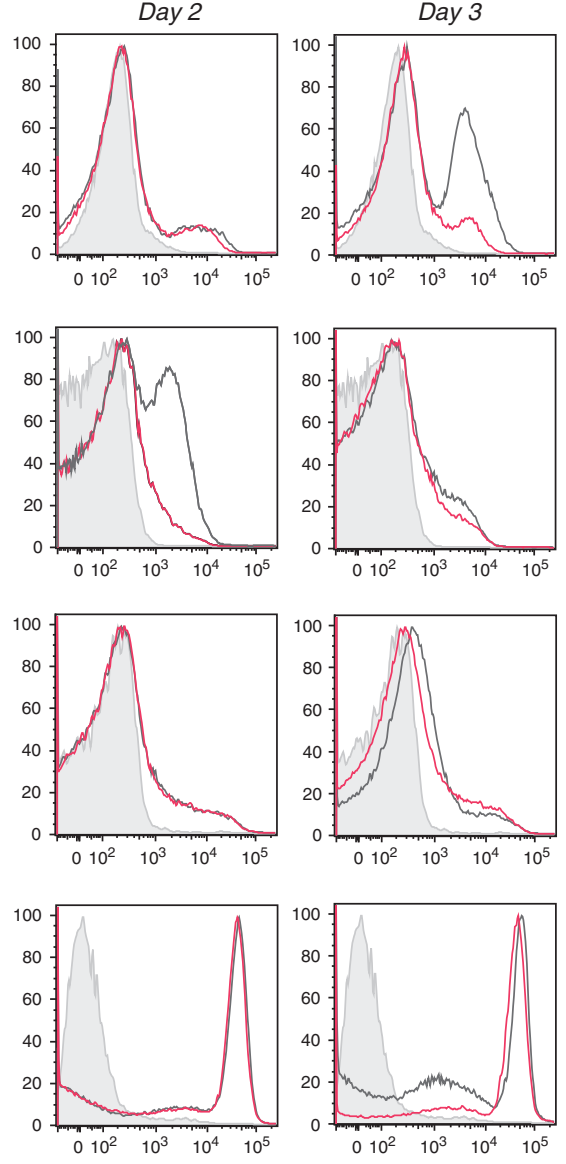
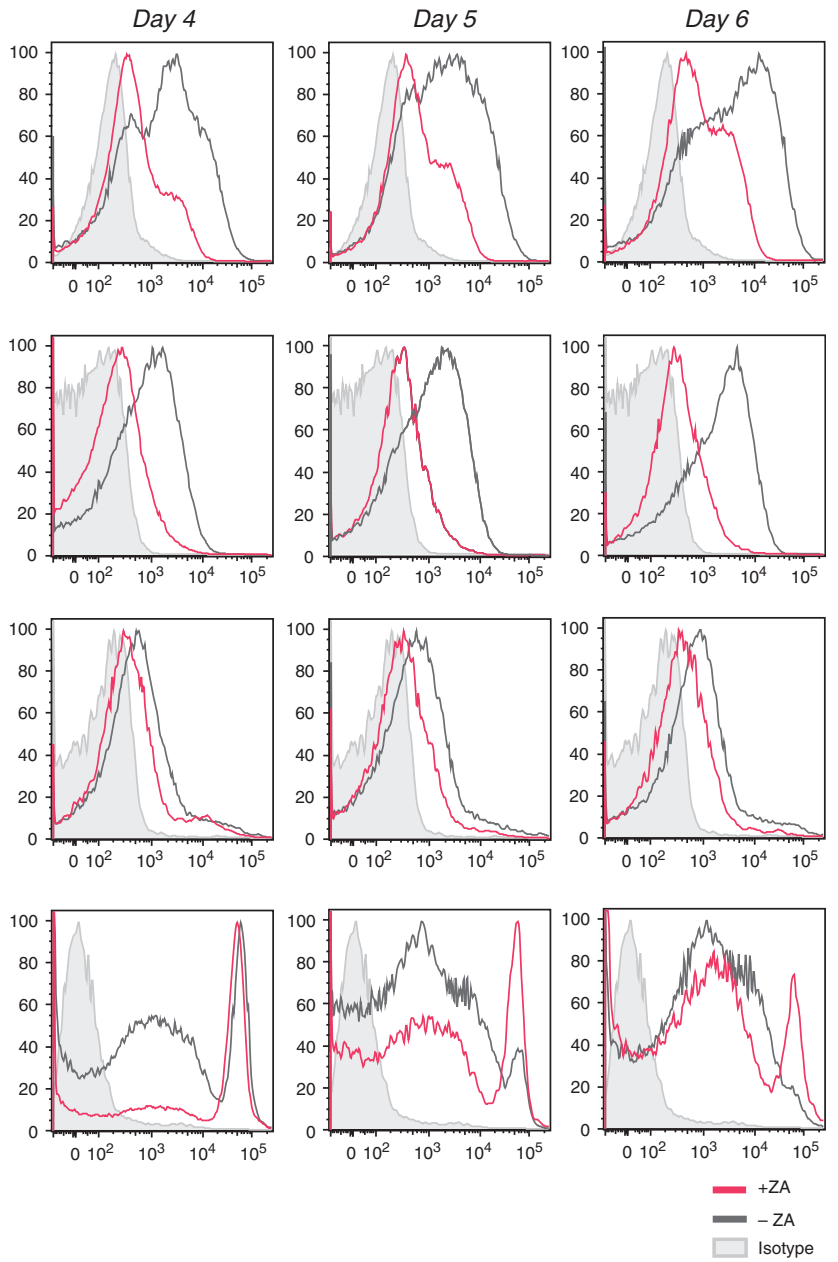

B
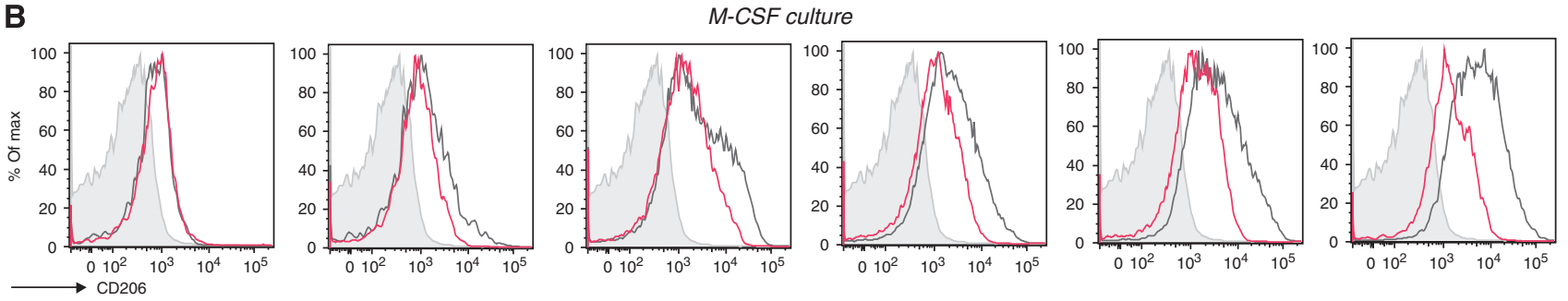

$30 \%$ tumour supernatant culture
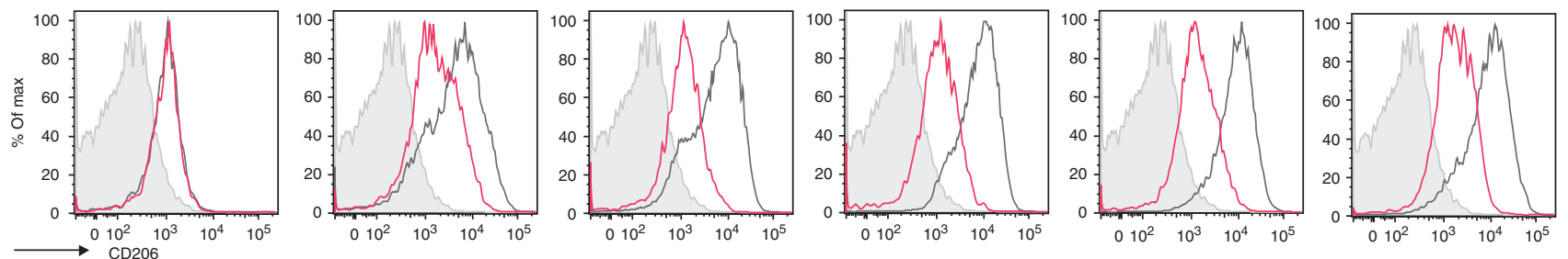

Figure 3 ZA inhibits the upregulation of extracellular markers in vitro. Expression profiles of M-CSF and RPMI containing 30\% tumour supernatant cultured cells were measured by FACS to determine the effect of ZA addition to the culture $\left(0.5 \mu \mathrm{g} \mathrm{ml} \mathrm{l}^{-1} \mathrm{M}-\mathrm{CSF} ; 0.30 \mu \mathrm{M}\right.$ ZA was added on day 0$)$. CD206 on macrophages was analysed to determine changes in macrophage phenotype. (A) M-CSF culture. F4/80, CDI IC and MHCll were upregulated within 6 days. The immature myeloid marker Gr-I was rapidly downregulated. The addition of ZA to the culture supernatant reduced the upregulation F4/80 and $\mathrm{MHCll}$ and $\mathrm{CDI}$ I c, leading to a significant difference in MFI of these markers on day 6 of culture $(P=0.003,0.0023,0.0003$, respectively). As a consequence, the expression of $\mathrm{Gr}-\mathrm{I}$ was still high in a majority of the cells after 6 days of culture. (B) CD206 expression on macrophages (M-CSF culture and 30\% tumour supernatant culture). After day 5 , almost all F4/80 $\mathrm{MHCll}^{+}$cells in the $\mathrm{M}$-CSF culture expressed CD206. The upregulation of CD206 on cells cultured in the presence of tumour supernatant was more explicit. The addition of ZA to the cultures reduced the expression of CD206 on macrophages in both conditions and a significant reduction in the MFI of CD206 on macrophages after 6 days of culture $(P<0.000 \mathrm{I})$. Experiments were repeated several times under comparable conditions $(n=5)$. Determination of the significance of peak shifts was based on calculation of the MFI. 
In both culture conditions there was a rapid decline in the number of cells expressing the immature marker Gr-1; however, the downregulation of Gr-1 was delayed when $\mathrm{ZA}$ was added to the culture. Simultaneously, a delay in the upregulation of macrophage markers was observed when ZA was added. The delay in the downregulation of $\mathrm{Gr}-1$ and the upregulation of F4/80 and MHCII was dose dependent, leading to a reduced number of mature macrophages after 6 days of culture when ZA was added to the culture (Figure 2). The total number of cells within the different culture conditions did not significantly change over time.

To summarise, we observed an inhibition of myeloid differentiation to macrophages when $\mathrm{ZA}$ was added to the culture conditioned for macrophages. This inhibitory effect on differentiation was dose dependent and led to significant differences in the number of macrophages and immature cells between the different culture conditions on day 6 . Furthermore, we showed that tumourderived factors present in tumour supernatant induced the development of macrophages from bone marrow-derived cells.

\section{Zoledronic acid shifts the balance from M2 macrophages to M1 macrophages in vitro}

To investigate the influence of ZA on the differentiation of myeloid progenitor cells to macrophage phenotypes, bone marrow cells were cultured in the presence or absence of $0.30 \mu \mathrm{M} \mathrm{ZA}$. Cells were cultured with M-CSF or $30 \%$ tumour supernatant as described previously (Wan et al, 2007, 2009; Tsagozis et al, 2008). The mannose receptor CD206 is a specific marker for M2 macrophages; therefore, the expression of this marker was analysed during culture to observe changes in macrophage phenotype (Mantovani et al, 2002).

Both M-CSF and 30\% tumour supernatant culture conditions revealed that macrophage markers, F4/80, CD11c and MHCII, were rapidly upregulated within 6 days of culture. Simultaneously, the marker for immature myeloid cells Gr-1 was downregulated. However, the addition of ZA to the culture significantly inhibits the upregulation of F4/80, MHCII and especially CD11c, leading to a significant difference in mean fluorescent intensity (MFI) of these markers on day 6 of culture $(P=0.003,0.0023$ and 0.0003 , respectively). The expression of Gr-1 remained high in both these culture conditions (Figure 3A).

On day 1, cells expressed CD206 at low levels; however, at day 2 of culture, a slight increase was found in both conditions. This upregulation persisted in the following days in the M-CSF culture conditions. In those conditions where ZA was added to the M-CSF culture, the upregulation of CD206 was abolished. The upregulation of CD206 took place earlier in the tumour supernatant conditions compared with the M-CSF culture. As a consequence, the blocking effect of ZA on the generation of M2 macrophages was more profound, leading to a complete inhibition in the upregulation of $\mathrm{CD} 206$ by $\mathrm{ZA}$ and a significant reduction in the MFI of CD206 on macrophages after 6 days of culture $(P<0.0001)$ (Figure 3B).

In conclusion, these data showed that the addition of $\mathrm{ZA}$ to macrophage-inducing culture conditions significantly inhibits the upregulation of F4/80, MHCII and CD11c. In addition, these data reveal that addition of tumour supernatant leads to polarisation of the macrophage phenotype towards $\mathrm{M} 2$, and that ZA can prevent this polarisation in vitro, leading to a significant reduction in the MFI of CD206 on macrophages cultured in the presence of ZA $(P<0.0001)$.

\section{Zoledronic acid does not improve survival in a murine tumour model}

Next, we investigated whether treatment with ZA had an effect on survival. Mice were i.p. inoculated with AC29 tumour cells and
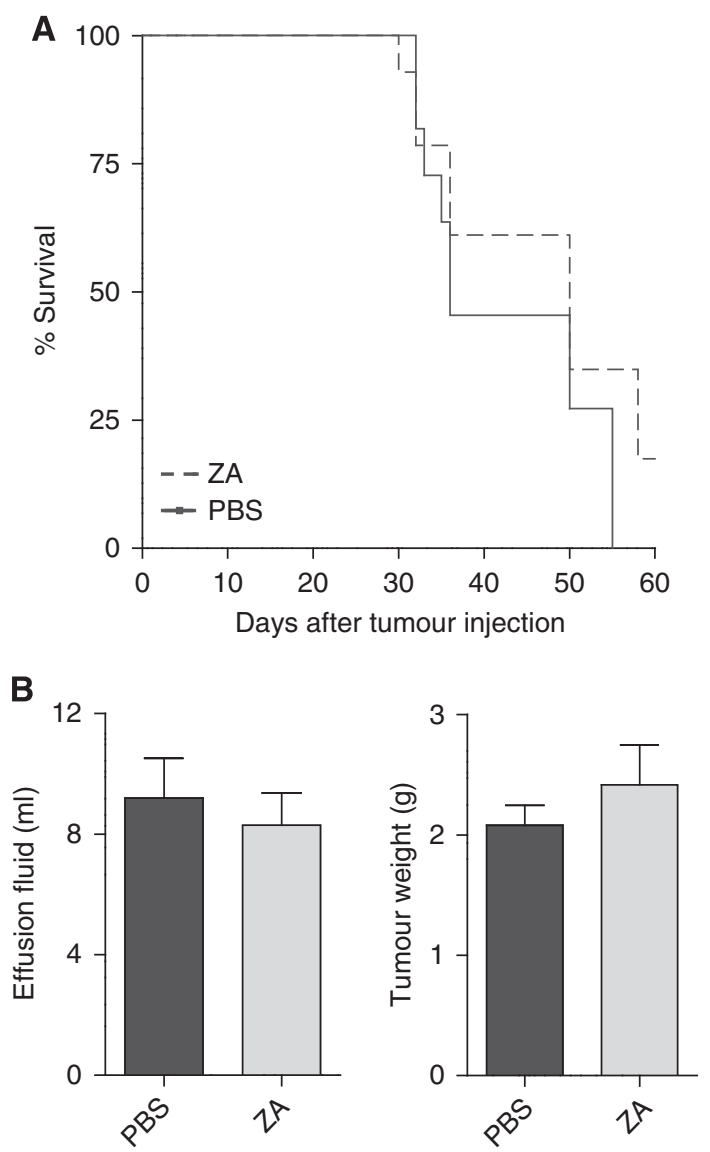

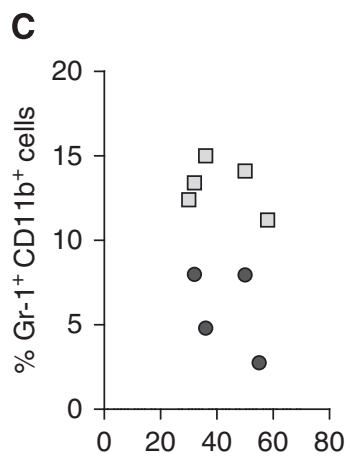

Days after tumour injection

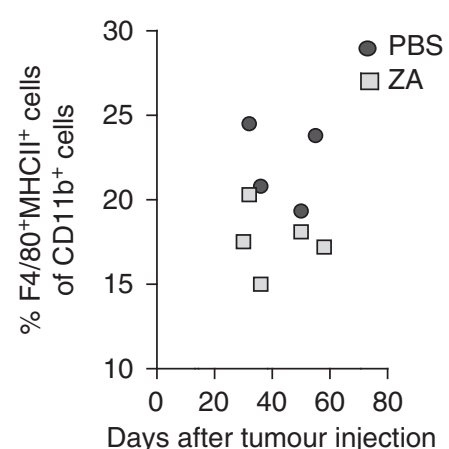

Figure 4 Treatment with ZA does not improve survival. Mice were divided into two groups ( $n=10$ mice per group). Mice were treated daily with s.c. ZA ( $100 \mu \mathrm{g} \mathrm{kg}^{-1}, \sim 2.5 \mu \mathrm{g}$ per mice) or PBS injections starting on day 5 after tumour injection. This dosing schedule was proven effective and non-toxic (Stathopoulos et al, 2008). Mice were killed when found profoundly ill. No significant improvement of survival was measured. (A) Kaplan-Meier survival curve. No significant differences in survival were observed between mice treated daily with s.c. injection of ZA compared with untreated mice $(P=0.3675)$. (B) Malignant effusions and tumour weights. Tumour weight and the amount of malignant effusion were measured when mice were killed. The effusion fluid was removed from the peritoneal cavity by fine-needle aspiration and all visible tumour material was collected. No significant differences in tumour weight or the amount of malignant effusion were observed $(P=0.42$ and 0.61$)$. (C) Myeloid cell types in the spleen of tumour-bearing mice. Long-term treatment effects were observed in the number of myeloid cells within the spleen of tumourbearing mice, implicating that higher numbers of myeloid precursors and lower numbers of TAMs were detected in mice treated with ZA compared with untreated mice. 
treated daily with s.c. ZA injections or PBS as a control. The dosing schedule was chosen according to the literature, in which it was proven effective and non-toxic (Stathopoulos et al, 2008). Mice were weighted on a daily basis and killed when found profoundly ill. The effusion fluid was collected when mice were killed.

No significant prolongation of survival was observed upon treatment with ZA $(P=0.2183)$ (Figure $4 \mathrm{~A})$. No significant differences were found in the total body weight or in the amount of effusion fluid volume during the experiment $(P=0.4178$ and 0.6103, respectively) (Figure 4B). Long-term treatment effects showed that higher numbers of myeloid precursors and lower numbers of TAMs were detected in mice treated with ZA compared with untreated mice; however, no effects were found in tumour burden and survival (Figure 4C).

Taken together, although no significant differences on tumour progression and survival could be observed between untreated mice and mice treated with $\mathrm{ZA}$, a reduction in the number of macrophages and an increase in the number of immature myeloid cells was detected.

\section{Identification of myeloid cells in vivo}

To establish whether ZA inhibits myeloid differentiation in tumour-bearing mice, myeloid cell types within the spleen, tumour and peritoneal cavity of tumour-bearing mice were identified. Recently, it has been shown that the heterogeneous group of MDSC consists of three major groups: polymorph nuclei CD11b ${ }^{\text {high }} \mathrm{Gr}$ $1^{\text {high }}$ MDSC (PMN-MDSC), mononuclear CD $11 b^{\text {high }} \mathrm{Gr}-1^{\text {int }}$ MDSC (MO-MDSC) and the CD11 $\mathrm{b}^{\text {high }} \mathrm{Gr}-1^{\text {low }}$-MDSC (Greifenberg et al, 2009). Identification of MDSC subtypes was carried out on cells of untreated tumour-bearing mice 25 days after tumour inoculation. The population of PMN-MDSC produces high levels of reactive oxygen species leading to the downregulation of the $\zeta$-chain of $\mathrm{T}$ cells, resulting in T-cell tolerance, whereas MO-MDSC can directly inhibit T-cell expansion by the production of nitric oxideinducing T-cell apoptosis (Bronte and Zanovello, 2005; Nagaraj and Gabrilovich, 2007; Gabrilovich and Nagaraj, 2009).

A massive increase in MDSC was found in the spleens and effusion fluids from the peritoneal cavity of tumour-bearing mice on day 25 after tumour injection. MDSCs were further subdivided into three groups: PMN-MDSC, MO-MDSC and Gr-1 ${ }^{\text {low }}$-MDSC. All subgroups of MDSC stained intermediate positive for the marker CD206 (Figure 5A). Expression of the markers F4/80 and MHCII was found on MO-MDSC and Gr-1 $1^{\text {low }}$-MDSC, but not on PMN-MDSC. A small subpopulation of the MO-MDSC was strongly positive for F4/80, MHCII and CD206 (Figure 5A).

In the peritoneal cavity and in the spleen, M1 and M2 macrophages were identified based on the expression of F4/80, MHCII and $\mathrm{CD} 206$, and forward-sideward scatter patron. M2 macrophages express higher levels of CD206 and F4/80 and lower levels of MHCII compared with the M1 macrophage population (Figure 5B).

New insights have revealed that MO-MDSC are pluripotent and under certain conditions are able to differentiate into TAMs (Rossner et al, 2005; Umemura et al, 2008; Greifenberg et al, 2009; Dolcetti et al, 2010). This is also reflected in vivo, as the population of MO-MDSC already showed partial expression of F4/80 and MHCII in an early stage compared with PMN-MDSC. To confirm that MO-MDSC could further differentiate into macrophages, we sorted this population from the spleen of tumour-bearing mice and cultured the cells for 5 days in the presence of M-CSF. Mononuclear-MDSC upregulated the expression of F4/80 and MHCII rapidly, in contrast to the PMN-MDSC that were not able to upregulate F4/80 under the influence of M-CSF (Figure 5C).

To summarise, we were able to identify three populations of MDSC as described in the literature in our tumour model. The MO-MDSCs were found to be able to differentiate into macrophages. Two populations of macrophages based on CD206 expression were found both in the spleen and in the peritoneal cavity of tumour-bearing mice.

\section{Zoledronic acid reduces macrophages but increases the number of immature myeloid cells during tumour development}

As we observed a difference in the number of macrophages and immature myeloid cells during ZA treatment, we next wanted to know whether ZA treatment also affects macrophage phenotype in vivo. To investigate whether $\mathrm{ZA}$ influences the development of macrophages during tumour progression in vivo, mice were i.p. inoculated with AC29 tumour cells and treated daily with s.c. ZA injections $\left(100 \mu \mathrm{g} \mathrm{kg}^{-1}, \sim 2.5 \mu \mathrm{g}\right.$ per mice) or PBS as a control. Mice were killed 25 days after tumour injection.

An increase in $\mathrm{CD} 1 \mathrm{bb}^{+} \mathrm{Gr}-1^{+}$cells was found in the spleen and effusion fluid of tumour-bearing mice of both groups. A significant increase was found in MO-MDSC both in the spleen and in the effusion fluid from the peritoneal cavity (spleen: $P=0.0312$; effusion fluid: $P=0.034$ ), whereas no significant differences were found in the proportion of PMN-MDSC and Gr- ${ }^{\text {low }}$-MDSC (spleen: $P=0.77$ and 0.75 ; effusion fluid: $P=0.74$ and 0.72 ). The proportion of macrophages in the spleen of ZA-treated mice was significantly lower compared with PBS-treated mice $(P=0.0091)$. There was a trend towards a shift in macrophage phenotype from M2 to M1; however, the reduction in M2 macrophages was not significant $(P=0.18)$. However, we found that the expression levels of CD206, expressed as the MFI, were significantly lower on M2 macrophages of ZA-treated mice compared with M2 macrophages in the spleen of PBS-treated mice $(P=0.0095)$ (Figure 6A). No significant decrease was found in the percentage of macrophages in the effusion fluid of ZA-treated mice $(P=0.75)$. However, a significant increase in M1 macrophages was found, while M2 macrophages were reduced $(P=0.035$ and 0.33$)$. A shift from M2 macrophage to M1 macrophage phenotype was found based on the MFI expression of CD206, confirming the findings in the spleen $(P=0.14)$. As a result, a difference in ratio of M1:M2 was found $(P=0.011)$ (Figure 6B).

Enzyme-linked immunosorbent assay on the effusion fluid was performed to determine whether the reduction on CD206 expression on macrophages in ZA-treated mice was accompanied by changes in cytokine, chemokine and growth factor production. A significant increase was found in the levels of IL-6, IL-12 and IL- $1 \beta$ in the effusion fluid of ZA-treated mice $(P=0.049,0.042$ and 0.005 , respectively). In addition, we observed a significant reduction in VEGF and CCL-2 (MCP-1) in the effusion fluid of ZA-treated animals $(P=0.05$ and 0.039$)$. Levels of IL-10 and TNF $\alpha$ were not detectable in the effusion fluid.

In conclusion, we have shown that treatment with ZA reduces the number of macrophages, but at the same time, we observed higher levels of immature myeloid cell types. When we further defined the population of immature myeloid cells, significantly more MO-MDSC were found. In addition, we found that the expression of CD206 on macrophages was lower in ZA-treated animals. This reduced expression of the M2 macrophages marker was accompanied with a significant reduction in VEGF and CCL-2 (MCP-1) levels and a significant increase in the levels of IL-6, IL-12 and IL-1 $\beta$ (Figure 6C).

\section{DISCUSSION}

Many effects of bisphosphonates have been reported in literature. Treatment with ZA prolongs the 1-year survival rate in breast cancer, prostate cancer and bladder cancer (Gnant, 2009; Rajpar et al, 2010; Zaghloul et al, 2010). However, exact mechanisms by which ZA prevents disease progression is still a topic of investigation. The role of bone formation and mineralisation in 
relation to adhesion and tumour outgrowth in these structures has gained interest after treatment with bisphosphonates appear to have protective effects on the prevention of bone metastasis
(Boissier et al, 1997, 2000; Magnetto et al, 1999; Montague et al, 2004). Besides the reduction in bone metastasis, studies have shown that $\mathrm{ZA}$ also prevents metastasis to secondary organs
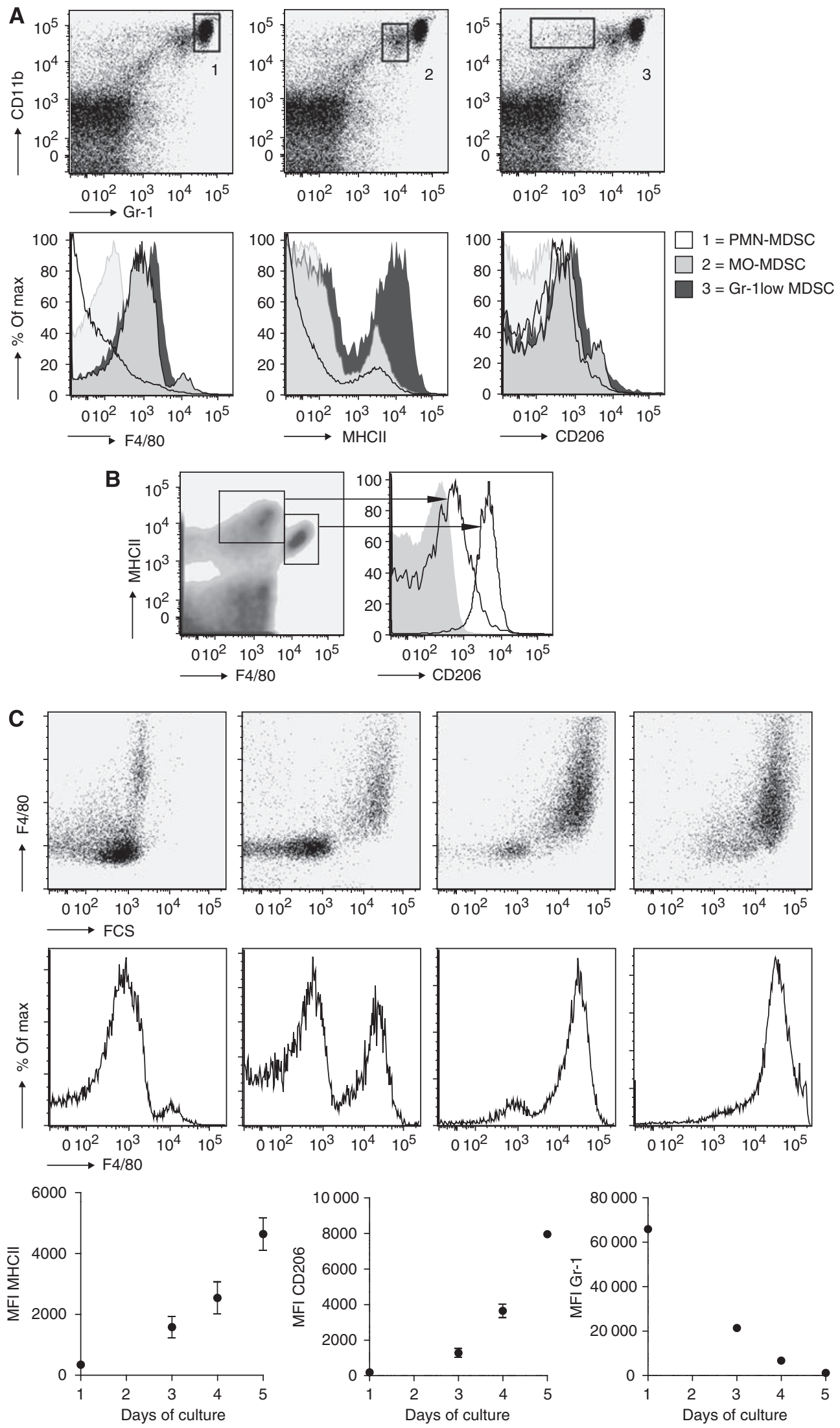
(Hiraga et al, 2004). Therefore, other mechanisms, during tumour progression, may be influenced by ZA treatment. Recently, it has been suggested that ZA may work as immune modulator and may therefore be applicable as and antitumour agent (Clezardin, 2005; Tsagozis et al, 2008; Santini et al, 2010).

$\mathrm{ZA}$ is an aminobisphosphonate that targets the mevalonate pathway in myeloid cells (Wolf et al, 2006). Recently, several clinical trails have been performed to investigate the role of $\mathrm{ZA}$ in tumour progression (Saad et al, 2002, 2004; Gainford et al, 2005). It has been suggested that ZA has direct antineoplastic activity on tumour cells (Santini et al, 2003; Clezardin, 2005; Ohtsuka et al, 2005; Caraglia et al, 2007). However, other studies have shown that clinically observed effects of ZA treatment may also be explained by indirect mechanisms involving immune modulation.

Studies have shown that ZA eventually leads to stimulation and proliferation of gamma/delta $\mathrm{T}$ cells (Kunzmann et al, 2000; Miyagawa et al, 2001; Sato et al, 2005). Besides, direct effects of ZA on tumour cell have been reported in breast cancer, prostate and bladder cancer (Gnant et al, 2009; Rajpar et al, 2010; Zaghloul et al, 2010). However, more recently the effect of ZA on macrophages has gained interest. Macrophages are known to have a dominant role within the tumour microenvironment. Several studies have reported the importance of TAMs on tumour progression (Pollard, 2004; Sica et al, 2006, 2008; Sangaletti et al, 2008; Allavena et al, 2008b; Coffelt et al, 2009). We and others have shown that depleting TAMs with liposome-encapsulated clodronate inhibits tumour growth and prolongs survival (Zeisberger et al, 2006; Miselis et al, 2008).

As our in vitro data revealed that $\mathrm{ZA}$ inhibits the differentiation towards macrophages, our aim was to determine whether this inhibition in differentiation also led to a reduction in TAMs in vivo.

The percentage of macrophages in the spleen was significantly reduced in ZA-treated animals compared with the control group. In the effusion fluid, no significant difference was found in the total number of macrophages; however, a shift towards a more M1 macrophage phenotype was observed. Recent studies have shown that TAMs can be derived from certain subpopulations within the heterogeneous MDSC population (Rossner et al, 2005; Umemura et al, 2008; Greifenberg et al, 2009; Dolcetti et al, 2010). From these studies, it has been established that TAMs were mainly derived from the MO-MDSC population. A significant increase in MO-MDSC was found both in the spleen and in the effusion fluid of mice treated with ZA. As we found that ZA inhibits myeloid differentiation in vitro, it can be assumed that the significant increase in the MO-MDSC population found in ZA-treated mice compared with untreated mice are caused by similar inhibitory effects on myeloid differentiation. Inhibition of myeloid differentiation by ZA has also been reported by others (Wolf et al, 2006; Melani et al, 2007; Chen et al, 2009).

Tsagozis et al (2008) reported that ZA shifts TAMs from an M2-like phenotype to an M1-like phenotype, resulting in a reduction in TAM-associated cytokine production in vitro. We were able to confirm these data in vitro, but were also able to show that these changes also occur in vivo. A reduction in the M2-associated receptor (CD206) was found on macrophages in tumour-bearing mice treated with ZA. Changes in M2-associated cytokines, chemokines and growth factors were observed in the effusion fluid after ZA treatment. We showed that ZA lowered the levels of VEGF in the effusion fluid of tumour-bearing mice. The reduction in VEGF and MMP-9 expressions by macrophages under the influence of ZA has been described to prevent tumour neovascularisation (Santini et al, 2002; Giraudo et al, 2004; Vincenzi et al, 2005; Melani et al, 2007; Tsagozis et al, 2008). The production of MMPs and VEGF is known to be essential during tumour progression and especially facilitating metastases (Allavena $\mathrm{et} a \mathrm{al}$, 2008b; Coffelt et al, 2009).

Even though it was found that ZA inhibits myeloid differentiation and shifts the balance from M2 macrophage phenotype towards an M1 macrophage phenotype, this did not improve survival in our model. There are several explanations for this finding. One of the most striking findings was the increased levels of immature myeloid cells (MDSC) due to treatment with ZA. Recently, studies have reported the role of MDSC in tumour progression. MDSC are most known for their immune suppressive function and induction of tumour-specific T-cell tolerance facilitating tumour immune escape (Bronte and Zanovello, 2005; Nagaraj and Gabrilovich, 2007; Gabrilovich and Nagaraj, 2009). Therefore, the inhibition of myeloid development may lead to reduction in the number of TAMs, resulting in a higher number of MDSC, which also promote tumour progression.

A second reason as to why ZA has no effect on survival may be assigned to the shift in macrophage phenotype. As most studies showed that TAMs are polarised to an M2 phenotype that contribute to carcinogenesis, shifting the phenotype of macrophages to M1 seems promising. M1 macrophages produce less tumour growth-promoting soluble factors and can potentially kill tumour cells. However, the question rises whether shifting the phenotype in full-blown tumours is possible and whether repolarisation is as promising as believed previously (Mills et al, 1992; Mantovani et al, 2002; Weigert and Brune, 2008). Negative aspects of iNOS + M1 macrophages were also observed. Actually, these cells can kill tumour cells, but as a consequence procarcinogenic substances are released from dying cells, leading to enhanced angiogenesis and enhanced polarisation of M1 macrophages to an M2 phenotype (Weigert and Brune, 2008). Coscia et al. reported similar observation. In their study, repolarisation of the macrophage phenotype was most promising during early tumour development, resulting in prolonged tumour-free survival and overall survival. In addition, they notify that shifting the phenotype in a host with a large tumour burden can be hazardous and no effects of ZA administration were observed when in situ carcinomas had progressed. From their data, it appears that tumour development is inhibited when the induction of M2 macrophages can be post-poned. We observed similar findings: shifting the phenotype from M2 to M1 at later stages of tumourigenesis seems less effective. Therefore, it can be hypothesised that preventing the formation of M2 macrophages is a critical key in preventing tumour outgrowth during early stages of disease development.

A third explanation for the limited effect on survival could be that ZA has effects on processes during tumour development that

Figure 5 Identification of myeloid cells in tumour-bearing mice. To identify the effect of tumour growth on the recruitment of myeloid cells during tumour progression, mice were inoculated with tumour cells and killed on day $25(n=12)$. (A) Identification of myeloid cell types in splenocytes of tumour-bearing mice. Immature myeloid cells could be divided into three groups, as described in the literature (Greifenberg et al, 2009). The Gr-I low-MDSC showed intermediate expression of F4/80, MHCll and CD206. F4/80 expression was found in MO-MDSC, but not in PMN-MDSC. A small number of MO-MDSC expressed high levels of F4/80 MHCII and CD206. MHCll and CD206 expressions were low in PMN-MDSC. (B) Identification of type I and type II macrophages in splenocytes of tumour-bearing mice. Two populations of macrophages could be identified; a high expression of CD206 was found in the membrane of the population with a high expression of F4/80 but lower expression of MHCII. (C) M-CSF culture of MO-MDSC-sorted cell fraction. MO-MDSC were sorted from splenocytes of tumour-bearing mice and cultured with $0.5 \mu \mathrm{g} \mathrm{ml}{ }^{-1} \mathrm{M}$-CSF. The expression of F4/80, MHCIl, CD206 and Gr-I were measured on consecutive days. 
A
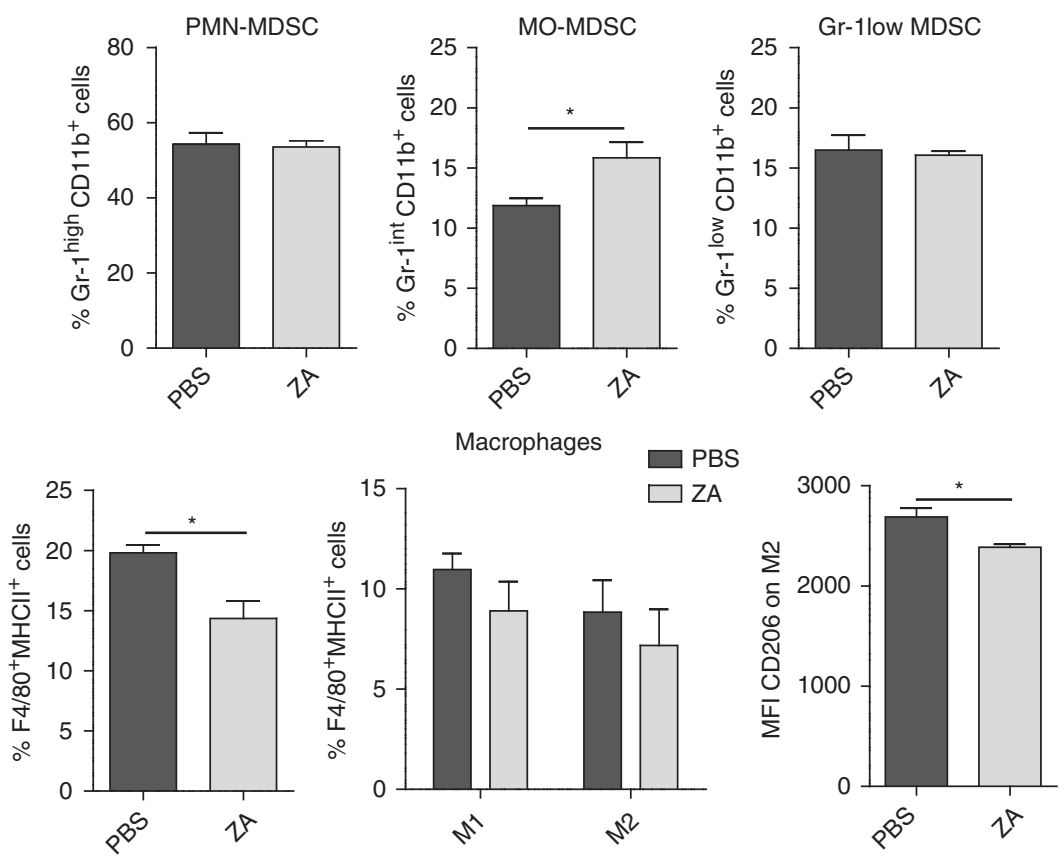

B
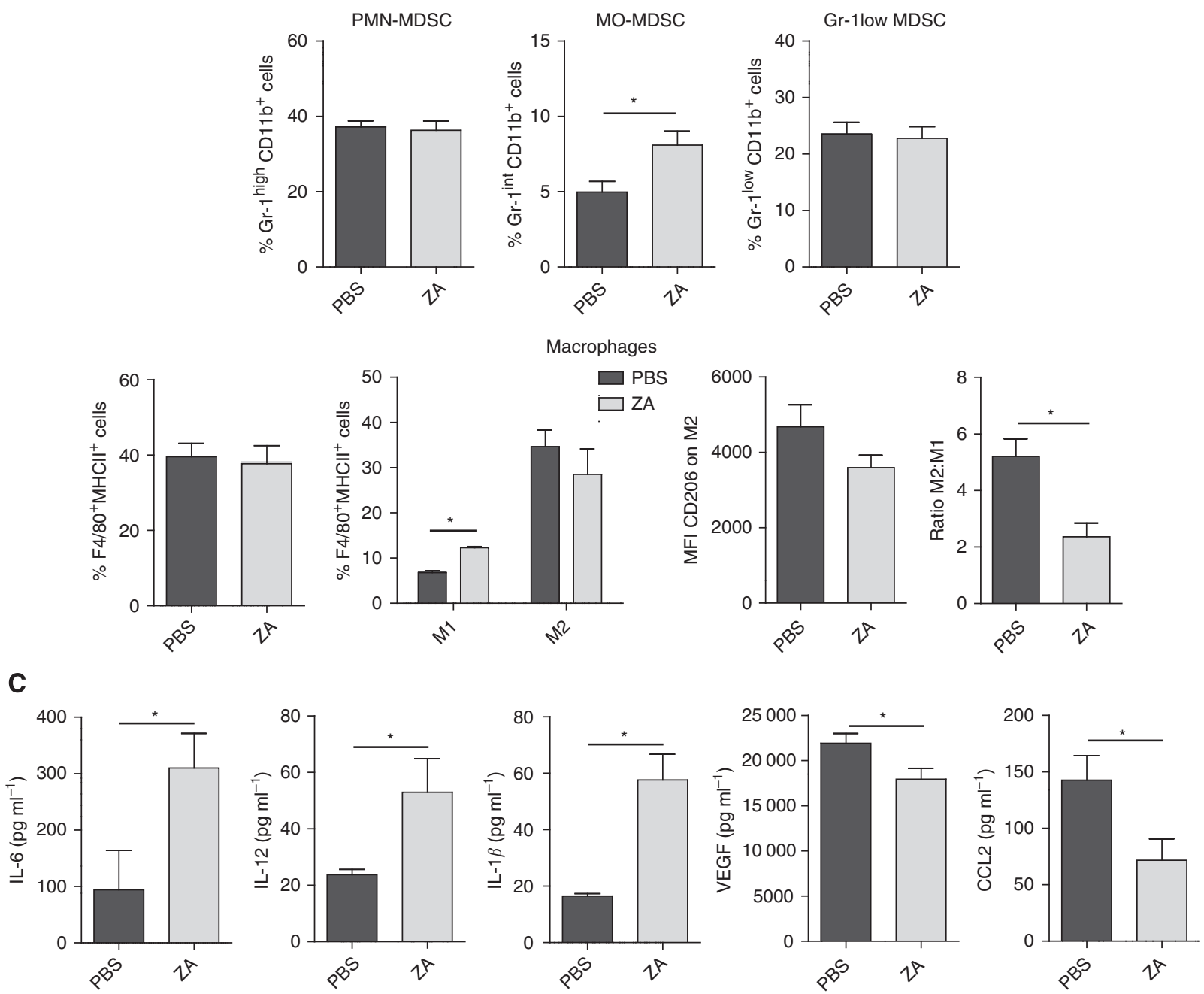
Figure 6 ZA changes MI:M2 ratio and increases MO-MDSC in tumour-bearing mice. Mice were i.p. inoculated with AC29 tumour cells and treated daily with s.c. injection of ZA. ( $100 \mu \mathrm{g} \mathrm{kg}{ }^{-1}$ ) or PBS as a control ( $n=6$ each group). Mice were killed 25 days after tumour injection. The number of MDSC was analysed according to the subdivision as described in Figure 5. Macrophages were subdivided into MI and M2 macrophages based on the co-expression of CD206, F4/80 and MHCll on the membrane. (A) Myeloid cell types in spleen of tumour-bearing mice. MO-MDSC were significantly increased in the spleen of ZA-treated animals ( $P=0.03$ I 2). No difference was found in the percentage of PMN-MDSC and Gr-I ${ }^{\text {low }}$-MDSC $(* P=0.77$ and 0.75$)$. The percentage of total macrophages in the spleen of ZA-treated mice was significantly lower compared with untreated mice $(* P=0.009 \mathrm{I})$. In the spleen of tumour-bearing mice, although not significant there was a trend towards a reduction in both $M I$ and $M 2$ macrophages in ZA-treated mice. In addition, ZA treatment significantly lowers the MFI of CD206 on M2 macrophages ( $P=0.0095$ ). (B) Myeloid cell types in effusion fluid of tumour-bearing mice. MO-MDSCs were significantly increased in the effusion fluid of ZA-treated animals (*P=0.034). No difference was found in the percentage of PMN-MDSC and Gr-I low MDSC or macrophages ( $P=0.72$ and 0.74$)$. A significant increase in $M I$ macrophages was found (* $P=0.035)$, and also an increase was found in the number of $\mathrm{M} 2$ macrophages ( $P=0.33)$. ZA shifts the balance, leading to a significant difference in the ratio of $M I: M 2$ macrophages (* $P=0.0 \mathrm{I} I)$; a trend towards a lower MFI of CD206 was observed $(* P=0.1 \mid 4)$. (C) Cytokines in effusion fluid of tumour-bearing mice. ELISA was performed on effusion fluid of tumour-bearing mice treated with ZA or PBS as a control. A significant increase in IL-6, IL-I 2 and IL-I $\beta$ was found in ZA-treated mice (* P = 0.049, 0.042 and 0.005 , respectively). A significant reduction in VEGF and CCL-2 (MCP-I) expressions was found in ZA-treated mice (*P $=0.05$ and 0.039$)$.

do not have a dominant role in our tumour models. Most investigations are carried out in tumours with high metastasis rates in combination with other therapeutic approaches (like adjuvant endocrine therapy) (Saad et al, 2002; Hiraga et al, 2004; Gnant, 2009). In these tumours, metastasis may be the cause of death, in contrast to our model. As TAMs do have an essential role in metastasis, ZA may be beneficial in these types of tumours (Allavena et al, 2008a). However, in both human studies and animal models, survival is only marginally influenced by ZA, and also in tumours with high metastases rates (Hiraga et al, 2004; Stathopoulos et al, 2008; Pandya et al, 2010; Ottewell et al, 2010).

To study the effects of $\mathrm{ZA}$ on macrophages in the primary tumour, dose levels are higher than clinically advised. Doses selected for clinical trials were based on changes in bone resorption markers (including serum $\mathrm{COOH}$-terminal telopeptide and urinary $\mathrm{N}$-telopeptide/creatinine ratio) and preliminary evidence of efficacy on skeletal-related events; however, no studies were performed comparing dose-effect relations on the tumour microenvironment. Although there are some concerns on side

\section{REFERENCES}

Allavena P, Sica A, Garlanda C, Mantovani A (2008a) The Yin-Yang of tumor-associated macrophages in neoplastic progression and immune surveillance. Immunol Rev 222: 155-161

Allavena P, Sica A, Solinas G, Porta C, Mantovani A (2008b) The inflammatory micro-environment in tumor progression: the role of tumor-associated macrophages. Crit Rev Oncol Hematol 66: 1-9

Boissier S, Ferreras M, Peyruchaud O, Magnetto S, Ebetino FH, Colombel M, Delmas P, Delaisse JM, Clezardin P (2000) Bisphosphonates inhibit breast and prostate carcinoma cell invasion, an early event in the formation of bone metastases. Cancer Res 60: 2949-2954

Boissier S, Magnetto S, Frappart L, Cuzin B, Ebetino FH, Delmas PD, Clezardin P (1997) Bisphosphonates inhibit prostate and breast carcinoma cell adhesion to unmineralized and mineralized bone extracellular matrices. Cancer Res 57: 3890-3894

Bronte V, Serafini P, Apolloni E, Zanovello P (2001) Tumor-induced immune dysfunctions caused by myeloid suppressor cells. J Immunother 24: $431-446$

Bronte V, Zanovello P (2005) Regulation of immune responses by L-arginine metabolism. Nat Rev Immunol 5: 641-654

Caraglia M, Marra M, Leonetti C, Meo G, D'Alessandro AM, Baldi A, Santini D, Tonini G, Bertieri R, Zupi G, Budillon A, Abbruzzese A (2007) R115777 (Zarnestra)/Zoledronic acid (Zometa) cooperation on inhibition of prostate cancer proliferation is paralleled by Erk/Akt inactivation and reduced Bcl-2 and bad phosphorylation. J Cell Physiol 211: $533-543$

Chen YJ, Chao KS, Yang YC, Hsu ML, Lin CP, Chen YY (2009) Zoledronic acid, an aminobisphosphonate, modulates differentiation and maturation of human dendritic cells. Immunopharmacol Immunotoxicol 31: 499-508

Claassen E (1992) Detection, localization and kinetics of immunomodulating liposomes in vivo. Res Immunol 143: 235-241 effects caused by ZA at higher levels (Ibrahim et al, 2003), additional studies are required to determine the safety and efficacy of increased dosages for this new application.

In conclusion, our data show that daily administration of $\mathrm{ZA}$ in tumour-bearing mice inhibits myeloid differentiation and shifts the balance from M2 macrophage phenotype to M1 macrophage phenotype. However, as a consequence the number of immature myeloid cells remains high in the spleen and in the effusion fluid, especially in the MO-MDSC population. This MO-MDSC population was found to have an immunosuppressive effect to which we ascribe the fact that survival was not improved with $\mathrm{ZA}$ in our study.

\section{ACKNOWLEDGEMENTS}

This study was financially supported by 'Stichting Asbestkanker Rotterdam'.

Clezardin P (2005) Anti-tumour activity of zoledronic acid. Cancer Treat Rev 31(Suppl 3): 1-8

Coffelt SB, Hughes R, Lewis CE (2009) Tumor-associated macrophages: effectors of angiogenesis and tumor progression. Biochim Biophys Acta 1796(1): $11-18$

Colotta F, Allavena P, Sica A, Garlanda C, Mantovani A (2009) Cancerrelated inflammation, the seventh hallmark of cancer: links to genetic instability. Carcinogenesis 30: 1073-1081

Condeelis J, Pollard JW (2006) Macrophages: obligate partners for tumor cell migration, invasion, and metastasis. Cell 124: 263-266

Coscia M, Quaglino E, Iezzi M, Curcio C, Pantaleoni F, Riganti C, Holen I, Monkkonen H, Boccadoro M, Forni G, Musiani P, Bosia A, Cavallo F, Massaia M (2009) Zoledronic acid repolarizes tumor-associated macrophages and inhibits mammary carcinogenesis by targeting the mevalonate pathway. J Cell Mol Med (accepted for publication)

Diel IJ, Jaschke A, Solomayer EF, Gollan C, Bastert G, Sohn C, Schuetz F (2008) Adjuvant oral clodronate improves the overall survival of primary breast cancer patients with micrometastases to the bone marrow: a longterm follow-up. Ann Oncol 19: 2007-2011

Diel IJ, Solomayer EF, Bastert G (2000) Bisphosphonates and the prevention of metastasis: first evidences from preclinical and clinical studies. Cancer 88: $3080-3088$

Dolcetti L, Peranzoni E, Ugel S, Marigo I, Fernandez Gomez A, Mesa C, Geilich M, Winkels G, Traggiai E, Casati A, Grassi F, Bronte V (2010) Hierarchy of immunosuppressive strength among myeloid-derived suppressor cell subsets is determined by GM-CSF. Eur J Immunol 40: 22 - 35

Fromigue O, Kheddoumi N, Body JJ (2003) Bisphosphonates antagonise bone growth factors' effects on human breast cancer cells survival. Br J Cancer 89: 178 - 184

Gabrilovich DI, Nagaraj S (2009) Myeloid-derived suppressor cells as regulators of the immune system. Nat Rev Immunol 9: 162-174 
Gainford MC, Dranitsaris G, Clemons M (2005) Recent developments in bisphosphonates for patients with metastatic breast cancer. BMJ 330: $769-773$

Giraudo E, Inoue M, Hanahan D (2004) An amino-bisphosphonate targets MMP-9-expressing macrophages and angiogenesis to impair cervical carcinogenesis. J Clin Invest 114: 623-633

Gnant M (2009) Bisphosphonates in the prevention of disease recurrence: current results and ongoing trials. Curr Cancer Drug Targets 9: 824-833

Gnant M, Mlineritsch B, Schippinger W, Luschin-Ebengreuth G, Postlberger S, Menzel C, Jakesz R, Seifert M, Hubalek M, Bjelic-Radisic V, Samonigg H, Tausch C, Eidtmann H, Steger G, Kwasny W, Dubsky P, Fridrik M, Fitzal F, Stierer M, Rucklinger E, Greil R, Investigators A-T, Marth C (2009) Endocrine therapy plus zoledronic acid in premenopausal breast cancer. $N$ Engl J Med 360: 679-691

Greifenberg V, Ribechini E, Rossner S, Lutz MB (2009) Myeloid-derived suppressor cell activation by combined LPS and IFN-gamma treatment impairs DC development. Eur J Immunol 39: 2865-2876

Hegmans JP, Hemmes A, Aerts JG, Hoogsteden HC, Lambrecht BN (2005) Immunotherapy of murine malignant mesothelioma using tumor lysatepulsed dendritic cells. Am J Respir Crit Care Med 171: 1168-1177

Hegmans JP, Hemmes A, Hammad H, Boon L, Hoogsteden HC, Lambrecht BN (2006) Mesothelioma environment comprises cytokines and T-regulatory cells that suppress immune responses. Eur Respir J 27: 1086-1095

Hiraga T, Williams PJ, Ueda A, Tamura D, Yoneda T (2004) Zoledronic acid inhibits visceral metastases in the $4 \mathrm{~T} 1 /$ luc mouse breast cancer model. Clin Cancer Res 10: 4559-4567

Ibrahim A, Scher N, Williams G, Sridhara R, Li N, Chen G, Leighton J, Booth B, Gobburu JV, Rahman A, Hsieh Y, Wood R, Vause D, Pazdur R (2003) Approval summary for zoledronic acid for treatment of multiple myeloma and cancer bone metastases. Clin Cancer Res 9: 2394-2399

Inaba $\mathrm{K}$, Inaba $\mathrm{M}$, Romani $\mathrm{N}$, Aya $\mathrm{H}$, Deguchi $\mathrm{M}$, Ikehara S, Muramatsu S, Steinman RM (1992) Generation of large numbers of dendritic cells from mouse bone marrow cultures supplemented with granulocyte/macrophage colony-stimulating factor. J Exp Med 176: 1693 - 1702

Kunzmann V, Bauer E, Feurle J, Weissinger F, Tony HP, Wilhelm M (2000) Stimulation of gammadelta $\mathrm{T}$ cells by aminobisphosphonates and induction of antiplasma cell activity in multiple myeloma. Blood 96: 384-392

Kusmartsev S, Gabrilovich DI (2002) Immature myeloid cells and cancerassociated immune suppression. Cancer Immunol Immunother 51: $293-298$

Magnetto S, Boissier S, Delmas PD, Clezardin P (1999) Additive antitumor activities of taxoids in combination with the bisphosphonate ibandronate against invasion and adhesion of human breast carcinoma cells to bone. Int J Cancer 83: 263-269

Mantovani A, Sozzani S, Locati M, Allavena P, Sica A (2002) Macrophage polarization: tumor-associated macrophages as a paradigm for polarized M2 mononuclear phagocytes. Trends Immunol 23: 549-555

Melani C, Sangaletti S, Barazzetta FM, Werb Z, Colombo MP (2007) Aminobiphosphonate-mediated MMP-9 inhibition breaks the tumor-bone marrow axis responsible for myeloid-derived suppressor cell expansion and macrophage infiltration in tumor stroma. Cancer Res 67: $11438-11446$

Mills CD, Shearer J, Evans R, Caldwell MD (1992) Macrophage arginine metabolism and the inhibition or stimulation of cancer. J Immunol 149: $2709-2714$

Miselis NR, Wu ZJ, Van Rooijen N, Kane AB (2008) Targeting tumorassociated macrophages in an orthotopic murine model of diffuse malignant mesothelioma. Mol Cancer Ther 7: 788-799

Miyagawa F, Tanaka Y, Yamashita S, Minato N (2001) Essential requirement of antigen presentation by monocyte lineage cells for the activation of primary human gamma delta $\mathrm{T}$ cells by aminobisphosphonate antigen. J Immunol 166: 5508-5514

Montague R, Hart CA, George NJ, Ramani VA, Brown MD, Clarke NW (2004) Differential inhibition of invasion and proliferation by bisphosphonates: anti-metastatic potential of Zoledronic acid in prostate cancer. Eur Urol 46: 389-401; discussion 401-2

Mundy G (2001) Preclinical models of bone metastases. Semin Oncol 28: $2-8$

Mundy GR (2002) Metastasis to bone: causes, consequences and therapeutic opportunities. Nat Rev Cancer 2: 584-593

Nagaraj S, Gabrilovich DI (2007) Myeloid-derived suppressor cells. Adv Exp Med Biol 601: $213-223$

Ohtsuka Y, Manabe A, Kawasaki H, Hasegawa D, Zaike Y, Watanabe S, Tanizawa T, Nakahata T, Tsuji K (2005) RAS-blocking bisphosphonate zoledronic acid inhibits the abnormal proliferation and differentiation of juvenile myelomonocytic leukemia cells in vitro. Blood 106: 3134-3141 Ottewell PD, Lefley DV, Cross SS, Evans CA, Coleman RE, Holen I (2010) Sustained inhibition of tumor growth prolonged survival following sequential administration of doxorubicin zoledronic acid in a breast cancer model. Int J Cancer 126: $522-532$

Pandya KJ, Gajra A, Warsi GM, Argonza-Aviles E, Ericson SG, Wozniak AJ (2010) Multicenter, randomized, phase 2 study of zoledronic acid in combination with docetaxel and carboplatin in patients with unresectable stage IIIB or stage IV non-small cell lung cancer. Lung Cancer 67(3): 330-338

Pollard JW (2004) Tumour-educated macrophages promote tumour progression and metastasis. Nat Rev Cancer 4: 71-78

Rajpar S, Massard C, Laplanche A, Tournay E, Gross-Goupil M, Loriot Y, Di Palma M, Bossi A, Escudier B, Chauchereau A, Fizazi K (2010) Urinary N-telopeptide (uNTx) is an independent prognostic factor for overall survival in patients with bone metastases from castrationresistant prostate cancer. Ann Oncol (in press)

Rossner S, Voigtlander C, Wiethe C, Hanig J, Seifarth C, Lutz MB (2005) Myeloid dendritic cell precursors generated from bone marrow suppress $\mathrm{T}$ cell responses via cell contact and nitric oxide production in vitro. Eur J Immunol 35: 3533-3544

Saad F, Gleason DM, Murray R, Tchekmedyian S, Venner P, Lacombe L, Chin JL, Vinholes JJ, Goas JA, Chen B (2002) A randomized, placebocontrolled trial of zoledronic acid in patients with hormone-refractory metastatic prostate carcinoma. J Natl Cancer Inst 94: 1458-1468

Saad F, Gleason DM, Murray R, Tchekmedyian S, Venner P, Lacombe L, Chin JL, Vinholes JJ, Goas JA, Zheng M (2004) Long-term efficacy of zoledronic acid for the prevention of skeletal complications in patients with metastatic hormone-refractory prostate cancer. $J$ Natl Cancer Inst 96: $879-882$

Sakaguchi S, Wing K, Onishi Y, Prieto-Martin P, Yamaguchi T (2009) Regulatory $\mathrm{T}$ cells: how do they suppress immune responses? Int Immunol 21: $1105-1111$

Sakaguchi S, Yamaguchi T, Nomura T, Ono M (2008) Regulatory T cells and immune tolerance. Cell 133: 775-787

Sangaletti S, Di Carlo E, Gariboldi S, Miotti S, Cappetti B, Parenza M, Rumio C, Brekken RA, Chiodoni C, Colombo MP (2008) Macrophagederived SPARC bridges tumor cell-extracellular matrix interactions toward metastasis. Cancer Res 68: 9050-9059

Santini D, Vespasiani Gentilucci U, Vincenzi B, Picardi A, Vasaturo F, La Cesa A, Onori N, Scarpa S, Tonini G (2003) The antineoplastic role of bisphosphonates: from basic research to clinical evidence. Ann Oncol 14: $1468-1476$

Santini D, Vincenzi B, Avvisati G, Dicuonzo G, Battistoni F, Gavasci M, Salerno A, Denaro V, Tonini G (2002) Pamidronate induces modifications of circulating angiogenetic factors in cancer patients. Clin Cancer Res 8: $1080-1084$

Santini D, Virzi V, Fratto ME, Bertoldo F, Sabbatini R, Berardi R, Calipari N, Ottaviani D, Ibrahim T (2010) Can we consider Zoledronic acid a new antitumor agent? Recent evidence in clinical setting. Curr Cancer Drug Targets 10(1): $46-54$

Sato K, Kimura S, Segawa H, Yokota A, Matsumoto S, Kuroda J, Nogawa M, Yuasa T, Kiyono Y, Wada H, Maekawa T (2005) Cytotoxic effects of gammadelta $\mathrm{T}$ cells expanded ex vivo by a third generation bisphosphonate for cancer immunotherapy. Int J Cancer 116: 94-99

Sica A, Larghi P, Mancino A, Rubino L, Porta C, Totaro MG, Rimoldi M, Biswas SK, Allavena P, Mantovani A (2008) Macrophage polarization in tumour progression. Semin Cancer Biol 18: 349-355

Sica A, Schioppa T, Mantovani A, Allavena P (2006) Tumour-associated macrophages are a distinct M2 polarised population promoting tumour progression: potential targets of anti-cancer therapy. Eur J Cancer 42: $717-727$

Siveen KS, Kuttan G (2009) Role of macrophages in tumour progression. Immunol Lett 123: $97-102$

Stathopoulos GT, Moschos C, Loutrari H, Kollintza A, Psallidas I, Karabela S, Magkouta S, Zhou Z, Papiris SA, Roussos C, Kalomenidis I (2008) Zoledronic acid is effective against experimental malignant pleural effusion. Am J Respir Crit Care Med 178: 50-59

Tsagozis P, Eriksson F, Pisa P (2008) Zoledronic acid modulates antitumoral responses of prostate cancer-tumor associated macrophages. Cancer Immunol Immunother 57: 1451- 1459

Umemura N, Saio M, Suwa T, Kitoh Y, Bai J, Nonaka K, Ouyang GF, Okada M, Balazs M, Adany R, Shibata T, Takami T (2008) Tumor-infiltrating myeloidderived suppressor cells are pleiotropic-inflamed monocytes/macrophages that bear M1- and M2-type characteristics. J Leukocyte Biol 83: 1136-1144 
Van Rooijen N, Sanders A (1994) Liposome mediated depletion of macrophages: mechanism of action, preparation of liposomes and applications. J Immunol Methods 174: 83-93

Vincenzi B, Santini D, Dicuonzo G, Battistoni F, Gavasci M, La Cesa A, Grilli C, Virzi V, Gasparro S, Rocci L, Tonini G (2005) Zoledronic acidrelated angiogenesis modifications and survival in advanced breast cancer patients. J Interferon Cytokine Res 25: 144-151

Wan H, Coppens JM, van Helden-Meeuwsen CG, Leenen PJ, van Rooijen N, Khan NA, Kiekens RC, Benner R, Versnel MA (2009) Chorionic gonadotropin alleviates thioglycollate-induced peritonitis by affecting macrophage function. J Leukocyte Biol 86: 361 - 370

Wan H, Versnel MA, Cheung WY, Leenen PJ, Khan NA, Benner R, Kiekens RC (2007) Chorionic gonadotropin can enhance innate immunity by stimulating macrophage function. J Leukocyte Biol 82: $926-933$
Weigert A, Brune B (2008) Nitric oxide, apoptosis and macrophage polarization during tumor progression. Nitric Oxide 19: 95-102

Wolf AM, Rumpold H, Tilg H, Gastl G, Gunsilius E, Wolf D (2006) The effect of zoledronic acid on the function and differentiation of myeloid cells. Haematologica 91: 1165-1171

Yoneda T, Michigami T, Yi B, Williams PJ, Niewolna M, Hiraga T (2000) Actions of bisphosphonate on bone metastasis in animal models of breast carcinoma. Cancer 88: $2979-2988$

Zaghloul MS, Boutrus R, El-Hossieny H, Kader YA, El-Attar I, Nazmy M (2010) A prospective, randomized, placebo-controlled trial of zoledronic acid in bony metastatic bladder cancer. Int J Clin Oncol (in press)

Zeisberger SM, Odermatt B, Marty C, Zehnder-Fjallman AH, Ballmer-Hofer K, Schwendener RA (2006) Clodronate-liposome-mediated depletion of tumour-associated macrophages: a new and highly effective antiangiogenic therapy approach. Br J Cancer 95: $272-281$ 